\title{
Research on Integrated Planning Method of Offshore Oil and Gas Exploration and Development
}

\author{
Xunda Wu \\ CNOOC-Zhanjiang Ltd., Zhanjiang, China
}

Email: 1248541271@qq.com

How to cite this paper: Wu, X.D. (2020) Research on Integrated Planning Method of Offshore Oil and Gas Exploration and Development. International Journal of Geosciences, 11, 483-491. https://doi.org/10.4236/ijg.2020.117024

Received: June 22, 2020

Accepted: July 18, 2020

Published: July 21, 2020

Copyright $\odot 2020$ by author(s) and Scientific Research Publishing Inc. This work is licensed under the Creative Commons Attribution International License (CC BY 4.0).

http://creativecommons.org/licenses/by/4.0/

\section{(c) (i) Open Access}

\begin{abstract}
Under the requirement of high-quality development, the research method of integrated model planning for offshore oil and gas exploration and development suitable for the western South China Sea is put forward. Based on the new round of resource evaluation and exploration and development research in the western South China Sea, the in-depth research on underground oil and gas resources, surface development facilities, external factors and economic indexes are carried out to clarify the industrial layout of oil and gas development. The potential and prospect of oil and gas exploration and development were implemented, and the main external factors and corresponding measures affecting the planning were clarified in this paper. The economic evaluation model suitable for the region is established based on the analysis of internal rate of return, comprehensive barrel oil cost, critical price, financial net present value and other important indicators, and a set of planning and research methods suitable for the integration of exploration and development in the western South China Sea is finally formed. This method has been applied to the replacement reserve study of Weizhou $\mathrm{X}$ and Weizhou $\mathrm{Y}$ oil fields. It is found that the planned reserves and production are consistent with the actual ones, and good practical results have been achieved.
\end{abstract}

\section{Keywords}

West of South China Sea, Integration of Exploration and Development, Planning, Reserves, Yield

\section{Research Background}

With the deepening of exploration, the level of refinement of oil and gas exploration in the western South China Sea is getting higher and higher, and the dif- 
ficulty of breakthroughs in exploration is becoming more and more difficult. In this study, the exploration, development, production and resources are coordinated, and a set of research methods of exploration and development suitable for the western South China Sea are developed, which provides a reliable basis for planning [1]. And the methods provide the necessary guarantee for exploration and development, which not only play a leading role in planning, but also clarify the planning objectives.

\section{Underground Oil and Gas Resources}

The western South China Sea is located in the western part of the northern continental shelf of the South China Sea in the west of 100 degrees east longitude, which mainly includes the Beibu Gulf Basin, Yinggehai Basin, Qiongdongnan Basin and the western part of the Pearl River Mouth Basin. It is rich in oil and gas resources. According to statistics, the total resources of the four basins in the western South China Sea are 3.92 billion tons of oil and 9.02 trillion cubic meters of natural gas.

From the perspective of underground resources, the potential of natural gas resources is far greater than the oil resources. By the end of 2018, the proved geological reserves of crude oil have reached 440 million tons, with a proven rate of $11 \%$; and the proved geological reserves of natural gas have reached 560 billion cubic meters, with a proven rate of $6 \%$. On the whole, the geological reserves to be proved of natural gas are high and the proven rate is low (Figure 1), so the industrial development pattern of "stabilizing oil and increasing gas" in the future has been defined.

Proved reserves planning is an important part of exploration planning. The first step is to analyze the parameters such as proved geological reserves, exploration well workload and single well exploration effect in historical years. Single well effect refers to the average proved geological reserves of each exploration well. It is the ratio of proved geological reserves and exploration well workload, which reflects the exploration effect in different fields and determines the planned proved land Planned exploration well workload corresponding to quality reserves. Through detailed big data analysis, we can sort out the laws of historical proved reserves, workload and effectiveness, and ensure that the prepared reserves planning scheme and workload planning scheme are reasonable and feasible [2].

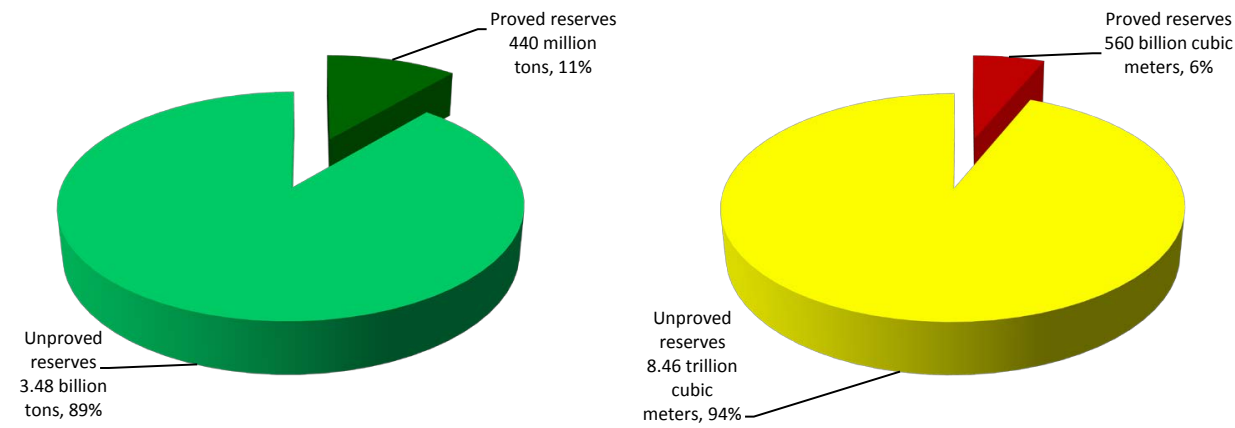

Figure 1. Oil and gas exploration rate in the Western South China Sea (2018). 
It is also very important to analyze the production degree and recovery factor of developed oil and gas fields. The production degree is the ratio of production reserves and geological reserves. Produced reserves refer to those reserves that really contribute to production. Recovery factor focuses the ratio of the quantity of crude oil produced to the produced reserves [3]. These two parameters are the "bridge" between the planned production and the corresponding planned proved reserves. It needs detailed big data analysis to determine the reasonable parameters. In addition, it is necessary to analyze the reserve production ratio, recovery degree and replacement factor. The reserve production ratio relates to the ratio of the remaining recoverable reserves at the beginning of the year to the oil production of the year, which means the number of years that the existing reserves are enough to maintain the current stable production level. Recovery degree involves the evaluation of the development effect of an oil field in which the cumulative oil production accounts for the oil and gas field at any time. Reserve replacement rate is the ratio of annual newly increased recoverable reserves to oil production in the same period, that is, the compensation rate of newly increased recoverable reserves to oil production in the same year.

Through the analysis of the important big data and parameters related to underground oil and gas resources [4], such as proved geological reserves, exploration well workload, single well exploration effect, oil and gas production degree, recovery rate, storage production ratio, recovery degree, replacement rate, etc., the relationship between planned production, planned proved reserves and planned exploration well workload is established [5]. The key parameters obtained through the analysis of exploration and development big data are used as links and bridges. The exploration and development plan can not only play a leading role in the exploration and development work, but also ensure the smooth realization of the planning objectives.

\section{Ground Production Facilities}

Ground production facilities mainly refer to production platforms, corresponding well slots and other production facilities, offshore oil and gas production pipelines, water supply and power supply facilities, etc. for offshore oil and gas fields. Based on the analysis of the underground oil and gas resources of offshore oil and gas fields, and guided by the concept of the integration of surface production facilities and underground oil and gas resources, the urgency of oil and gas reserves replacement is comprehensively analyzed, so as to guide the exploration and development planning and deployment scheme.

The design life of the platform refers to the remaining healthy service life of the platform design, the economic development life focuses the corresponding economic development life of underground oil and gas resources, and the reserve replacement window relates to the difference between the two. For a healthy development oil and gas production platform, its design life should match the economic development life. If the difference between the two is large, it means 
that the production platform needs to increase exploration reserves around, so as to increase the storage production ratio of oil and gas fields and extend the economic development period. Otherwise, it will face the situation that the underground oil and gas resources have been exploited in the future and the production facilities have been cut off in a healthy state. If the difference between the two is small or negative, it means that the underground oil and gas resources are abundant, and the production facilities can not be in healthy service until the underground resources are fully exploited. In this case, the plan of prolonging the service life of the platform facilities should be considered. Through the analysis of 37 offshore production platforms, it can be seen that $73 \%$ of the production platform reserve replacement windows in the analysis samples are between $0-10$, in a relatively healthy development state; $13.5 \%$ of the production platform reserve replacement windows are more than 10 , so it is urgent to find replacement reserves around its periphery and increase the oil and gas field reserve production ratio; $13.5 \%$ of the production platform reserve replacement windows are negative, so it is urgent to do a good job of the platform Prolong life, so as to guarantee the economic development of underground oil and gas resources (Figure 2).

In addition, the remaining well slots of the production platform, low production and shut-down wells are also the key factors for the evaluation of surface production facilities [6]. The distribution of the remaining well slots and whether the low production and shut-down wells have other potential blocks for sidetracking are important factors for the comprehensive adjustment of oil and gas fields. For example, for the oil and gas fields with many remaining well slots or low production and shut-down wells, it is necessary to increase the integrated evaluation of exploration and development around the oil field, find high-quality reserves, use the side drilling of remaining well slots or low production and shut-down wells to ensure the healthy and sustainable development of oil and gas fields (Figure 3).

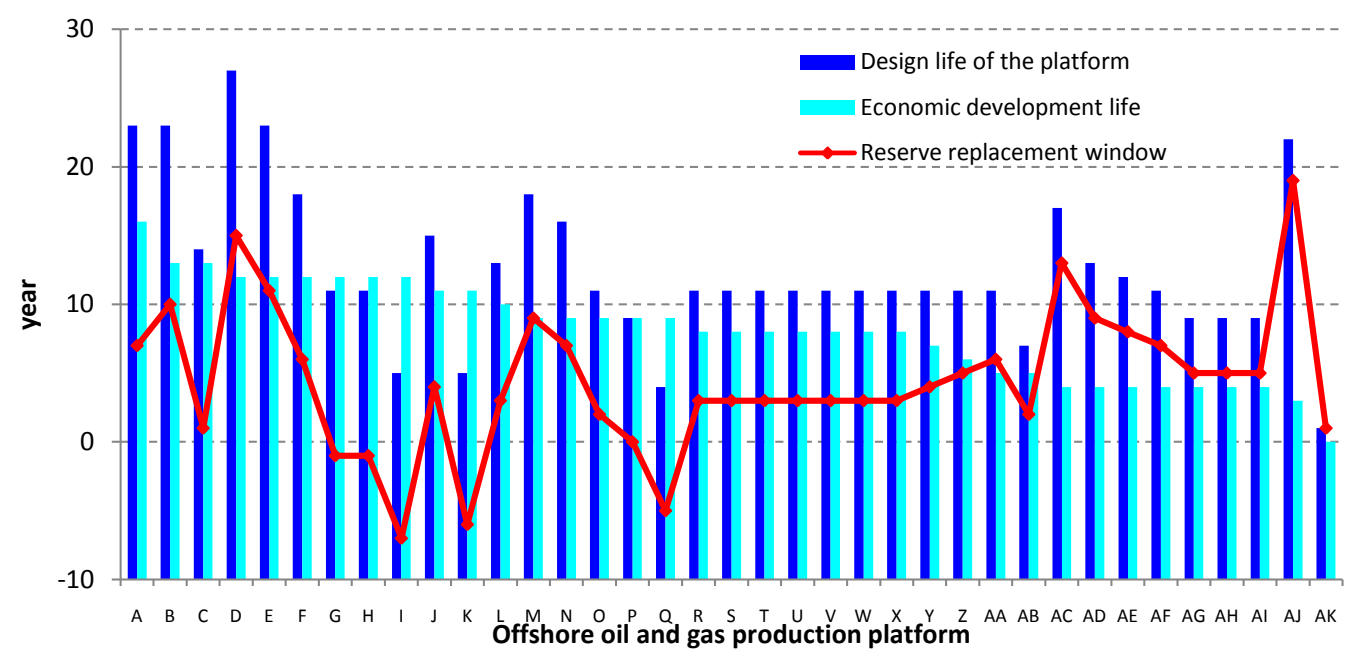

Figure 2. Integration analysis of offshore production facilities and underground oil and gas resources. 
Distribution of low production and discontinued Wells in the the production platform

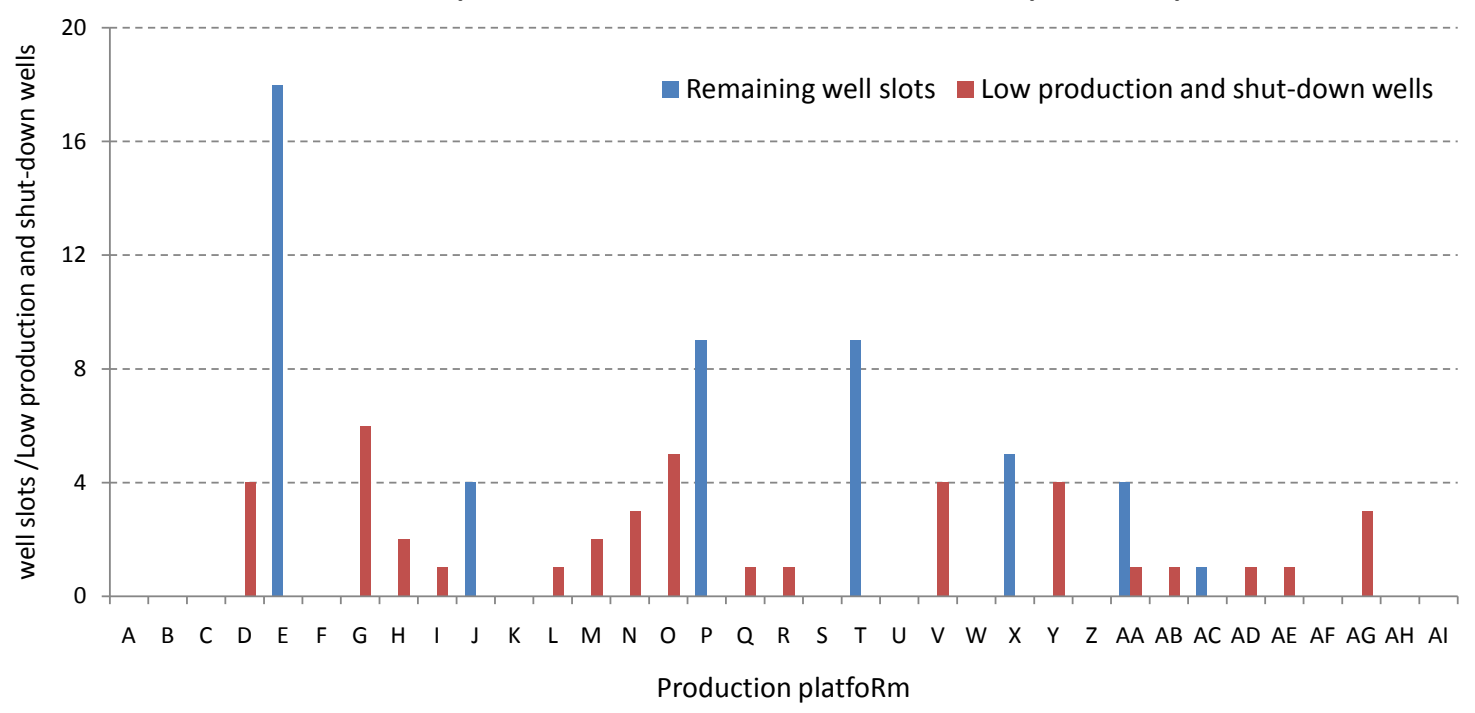

Figure 3. Distribution of remaining well slots and low production and shut-down wells in production platform.

To sum up, the research on surface production facilities is an important research content in the integrated planning and research of exploration and development [7]. The relationship between the design life of the platform and the economic development life directly determines the urgency of the integrated exploration and development of the potential around the platform. Whether the platform has remaining well slots or low production and shut-down wells directly determines the drilling conditions of the platform. Both of them are important contents of integrated planning and research of offshore oil and gas exploration and development.

\section{External Factors}

The natural gas market, the situation of mineral rights management and the corresponding national policies are also important external factors affecting the planning based on the research of underground oil and gas resources and surface development facilities.

The natural gas market and sales price have a direct impact on the promotion of undeveloped gas field projects and the internal adjustment of production gas fields. The implementation or evaluation of reasonable gas price in the natural gas sales market has a positive effect on the promotion of the project [8]. On the contrary, the project economy fails to meet the company's requirements on the benchmark yield, which makes it difficult to promote. For example, a gas field is a large-scale high-quality and high-yield gas field, with abundant proved geological reserves and expected large production capacity. However, the development of the gas field is affected by high technology and high investment. Users in the downstream market of natural gas need to reach a certain scale to promote the economic development of the gas field. Although the development of various technologies is progressing smoothly, it only owes "Dongfeng" to the down- 
stream market of natural gas. This means that the downstream market and the evaluation of gas price is an important research factor in the planning of natural gas production.

Mineral rights are the most basic "cultivation land" for the planning of exploration and development. On the basis of fully understanding the geological conditions of exploration and development, oil-bearing areas and mineral rights are overlapped in the software of mineral rights classification and planning system by the method of addition and equivalence, and the mineral rights are classified into class I, class II, class III and class IV mineral rights from superior to inferior. Class I and class II mineral rights are basically high-quality exploration and development areas, which need to invest a lot of exploration and development work every year, while class IV mineral rights are areas with poor geological conditions, which have less or even insufficient exploration and development work every year, and face the risk of withdrawal [9]. Therefore, in the process of planning, according to the situation of exploration and development, the workload should be planned and the blocks that need to be protected should be put into use at the critical moment. In addition, according to the exploration and development planning, the wells and seismic workload are carried out in proper blocks.

\section{Economic Model Indicators}

The main purpose of project evaluation in the planning stage is to embody the principle of maximizing exploration value in the exploration deployment, to discover more exploitable reserves with the optimal exploration investment [10]. In the aspect of project development, to use the discovered reserves in a planned way, so as to achieve the optimization of single project and the optimization of investment project portfolio under the condition of limited investment scale.

The core of economic evaluation is to take profit as the center and maximize the company's benefit. Through the evaluation and research of internal rate of return, comprehensive barrel oil cost, critical price, financial net present value and other important indicators, the concept of "full cycle cost" is introduced in the use efficiency of funds to achieve the purpose of promoting benefit priority and optimizing exploration and development deployment.

Economic evaluation should give priority to promoting benefit and optimizing exploration and development. Exploration deployment should focus on maximizing exploration value and finding more exploitable reserves with optimal exploration investment [11].

The development and deployment should pay attention to the optimization of reserves utilization and the scientific deployment of development plans to achieve the economic optimization; the strategic planning should emphasize the reasonable financial forecast and capital planning at the company level, and promote the implementation of the strategic planning.

The efficiency of capital use is a parameter to evaluate the effect of capital use. 
The main two indicators are the effectiveness and sufficiency of asset use. For example, the economic contribution of newly discovered reserves in exploration is totally different from that in development ten years later. Therefore, it is necessary to reexamine the barrel oil cost of exploration and discovery, and adhere to the inclination of oil and gas investment to high return and fast conversion areas.

To sum up, on the basis of in-depth research on four aspects of underground oil and gas resources, surface development facilities, external influencing factors and economic model indicators, a research system of integrated planning method for offshore oil and gas exploration and development is established (Figure 4). Thus, the industrial layout of oil and gas development is defined, the potential and prospect of oil and gas exploration and development are implemented, the main external factors affecting the planning and corresponding measures are clarified, the economic evaluation model suitable for the region is established, and finally a set of planning and research methods suitable for the integration of exploration and development in the western South China Sea are formed.

\section{Case Study}

The method of integrated exploration and development planning is applied to the replacement reserves of Weizhou X and Weizhou Y oilfields. Through the overall deployment, a number of exploration wells and development evaluation wells have been implemented in the two oilfields, and good results have been achieved in reserves and production [12].

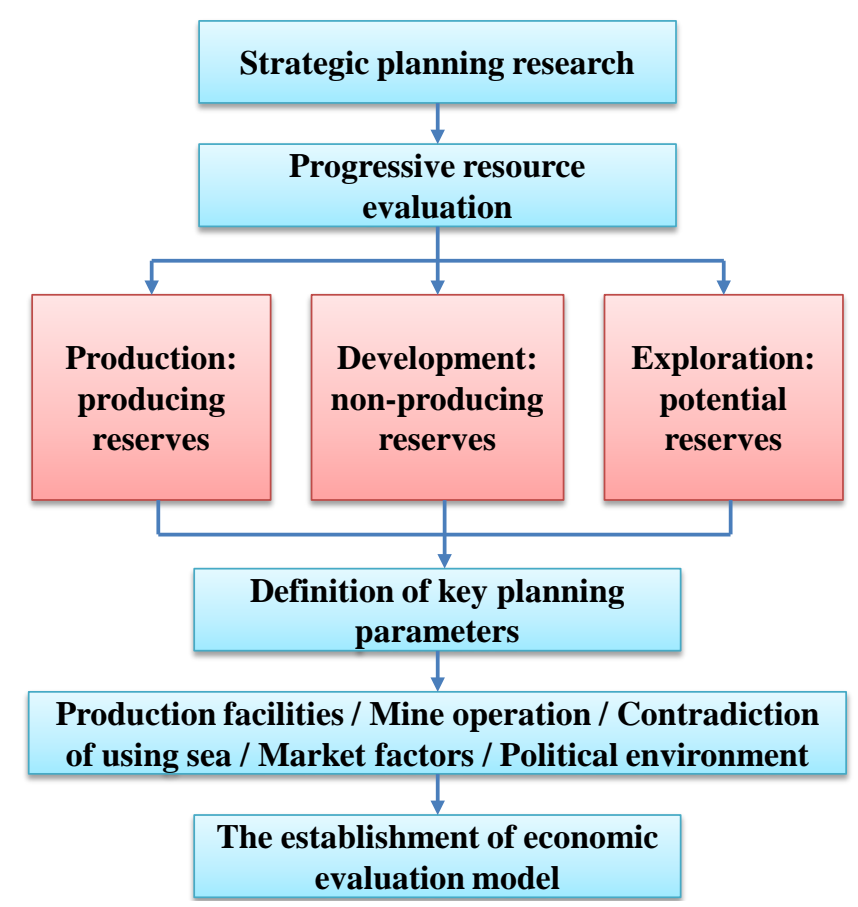

Figure 4. Research technology system of integrated exploration and development planning method. 
In the aspect of Weizhou X oilfield research, in January 2017, a number of exploration wells were deployed for a structural belt, with the newly proved geological reserves of more than 2 million cubic meters. Due to the unclear understanding of the single well productivity and dynamic reserve range in the low permeability layer of the target formation. In May 2017, relying on the production platform, through the implementation of development evaluation wells, the low-permeability production capacity of the target layer and its reserve production range were implemented. Three months before the production of the development evaluation well, the daily production is stable at about $100 \mathrm{~m}^{3}$, and the development effect is good. At the same time, the successful evaluation of the well is expected to promote the evaluation of similar sand bodies (resource potential of about 11 million $\mathrm{m}^{3}$ ) in the area, and accelerate the overall development deployment of $\mathrm{X}$ oilfield.

\section{Conclusions}

1) The successful application of the integrated exploration and development planning method in Weizhou $\mathrm{X}$ and Weizhou $\mathrm{Y}$ oilfields proves the effectiveness and reliability of the method in the western area of the South China Sea.

2) The original development concept design cannot be maintained, and the realization of the expected economic benefits will not be effectively guaranteed when there is a large difference between the expectation after drilling and before drilling in exploration/evaluation wells. The next research will focus on the basis of planning, optimization of planning research methods in order to ensure the realization of the planning scheme.

\section{Conflicts of Interest}

The author declares no conflicts of interest regarding the publication of this paper.

\section{References}

[1] Behrenbruch, P. (1993) Offshore Oilfield Development Planning. Journal of Petroleum Technology, 45, 735-743. https://doi.org/10.2118/22957-PA

[2] Back, M. (2016) Optimized Exploration Planning. SPE/ IAEE Hydrocarbon Economics and Evaluation Symposium, Houston, Texas, 17-18 May 2016, 13. https://doi.org/10.2118/179951-MS

[3] Thambydurai, R., Mustapha, A.F., Mueller, K.H. and Dixon, M.R. (1988) Jerneh Gas Reid Development Planning. Offshore South East Asia Show, Singapore, 2-5 February 1988, 859. https://doi.org/10.2118/17702-MS

[4] Shaw, M.N., Fowles, J.D., Abernethy, S. and Hamp, R. (1998) Laminaria/Corallina-An Integrated Field Development Planning Approach. SPE Asia Pacific Oil and Gas Conference and Exhibition, Perth, 12-14 October 1998, 497. https://doi.org/10.2118/50154-MS

[5] Cockcroft, P.J. and Moore, K.S. (1994) Development Planning: A Systematic Approach. SPE Asia Pacific Oil and Gas Conference, Melbourne, 7-10 November 1994, 395. https://doi.org/10.2118/28782-MS 
[6] Orudjev, S.A. and Muravlenko, V.I. (1975) RP (4) Integrated Planning for Exploration, Development, Production and Transportation for Rapid Expansion of Oil Field Operations. 9 th World Petroleum Congress, Tokyo, 11-16 May 1975, WPC-16234.

[7] Guyaguler, B. and Ghorayeb, K. (2006) Integrated Optimization of Field Development, Planning, and Operation. SPE Annual Technical Conference and Exhibition, San Antonio, Texas, 24-27 September 2006, 13.

https://doi.org/10.2118/102557-MS

[8] Davis, L.F. (1968) Economic Judgment and Planning in North American Petroleum Exploration. Journal of Petroleum Technology, 20, 467-474. https://doi.org/10.2118/2002-PA

[9] Holding, J. (1984) The Development Of A Highly-Integrated Offshore Oil and Gas Production System in the North Sea. Southeast Asia Show, Singapore, 21-24 February 1984, 5-44. https://doi.org/10.2118/12389-MS

[10] Barton, D.R., Clark, W.Y., Howard, W.J., Hudson, T.A., Newhouse, C. C., Martin, B.H., et al. (1999) Genesis Project: Development Well Planning. Offshore Technology Conference, Houston, Texas, 3-6 May 1999, 11.

https://doi.org/10.4043/10797-MS

[11] Shlyakhova, A., Jones, M.K., Kasumov, T.V. and Morgan, D. (2010) Pitun "Sub-Arctic" Offshore Integrated Oil and Gas Development. SPE Russian Oil and Gas Conference and Exhibition, Moscow, 26-28 October 2010, 11. https://doi.org/10.2118/135948-MS

[12] Lubnin, A.A., Afanasiev, I.S., Yudin, E.V., Fedorchenko, G.D., Sansiev, G.B. and Shchekin, A.I. (2015) System Approach to Planning the Development of Multilayer Offshore Fields. SPE Russian Oil and Gas Conference and Exhibition, Moscow, 26-28 October 2010, 20. https://doi.org/10.2118/176690-MS 